\title{
Genetic parameters for stayability in Murrah buffaloes
}

\author{
Priscilla M Galeazzi ${ }^{1}$, Maria EZ Mercadante ${ }^{2}$, Josineudson AIIV Silva ${ }^{3}$, \\ Rúsbel R Aspilcueta-Borquis ${ }^{1}$, Gregório MF de Camargo ${ }^{1}$ and Humberto Tonhati ${ }^{1}$ * \\ ${ }^{1}$ São Paulo State University - Animal Science Department - Jaboticabal-SP, Brazil \\ ${ }^{2}$ Animal Science Experimental Station of Sertãozinho-SP, Brazil \\ ${ }^{3}$ São Paulo State University - Animal Breeding and Nutrition Department - Botucatu-SP, Brazil
}

Received 25 March 2009; accepted for publication 8 January 2010

\begin{abstract}
In order to contribute to the breeding programmes of Asian water buffalo, the aim of this study was to analyse the influence of genetic effects in the stayability of Murrah dairy buffaloes. The stayability trait (ST) was defined as the female's ability to stay in the herd for one (ST1), two (ST2), three (ST3), four (ST4), five (ST5) or six years (ST6) after the first calving. The same trait was also considered as continuous and was designated stayability in days up to one (STD1), two (STD2), three (STD3), four (STD4), five (STD5) or six years (STD6) after the first calving. Data from 1016 females reared in nine herds located in the State of São Paulo, Brazil, were analysed. Statistical models included the additive genetic effect of the animal and the fixed effects of the buffalo breeding herd, birth year and birth season. Additive effects for ST were estimated by approximate restricted maximum likelihood using a threshold model, while for STD, the additive effects were estimated by restricted maximum likelihood. Heritability estimates were lower for ST, except for ST1, $(0 \cdot 11 \pm 0 \cdot 07,0 \cdot 17 \pm 0 \cdot 06,0 \cdot 23 \pm 0 \cdot 06,0 \cdot 16 \pm 0 \cdot 08,0 \cdot 14 \pm 0 \cdot 09$ and $0 \cdot 16 \pm 0 \cdot 10$ for ST1, ST2, ST3, ST4, ST5 and ST6, respectively) when compared with STD $(0 \cdot 05 \pm 0 \cdot 06$, $0 \cdot 18 \pm 0 \cdot 08,0 \cdot 40 \pm 0 \cdot 10,0 \cdot 49 \pm 0 \cdot 11,0 \cdot 41 \pm 0 \cdot 11$ and $0 \cdot 30 \pm 0 \cdot 13$, for STD1, STD2, STD3, STD4, STD5 and STD6, respectively). Considering the values of heritability and owing to the serial nature of STD to a specific age, selection for STD3 should have a favourable influence on STD to other ages.
\end{abstract}

Keywords: Bubalus bubalis, heritabilty, genetic parameters, longevity.

The Brazilian herd of buffalo is the largest herd outside the Asian continent. According to FAO (2009) there are around 1.2 million head of buffaloes in Brazil. While some of the Brazilian herd is utilized for meat production, most breeders aim at dairy farming owing to the attractive commercial profit that is associated with this activity. Such a profit comes mostly from the greater yield of dairy products, especially Mozzarella cheese (Tonhati et al. 2008).

Dairy females' longevity is a really important trait in a herd affecting overall profitability in the dairy industry. A high female longevity is desirable because the cost of rearing a heifer is high and moreover it allows a greater proportion of culling decisions to be based on production, instead of involuntary culling. Dairy females have been selected intensively for productivity traits whilst longevity within the herd has decreased. One measure of longevity is the stayability trait (Vollema \& Groen, 1996). Stayability

*For correspondence; e-mail: tonhati@fcav.unesp.br is defined here as the ability to stay in the herd measured in years after the first calving.

Early studies in dairy cattle indicated that stayability heritability was low $(0 \cdot 02-0 \cdot 05$; Hudson \& Van Vleck, 1981). Since then, many studies of the genetic variation of stayablity traits have been published, confirming the expressive environmental influence on this trait (Madgwick \& Goddard, 1989; Short \& Lawlor, 1992; Vukasinovic et al. 1997). Despite the lack of studies in buffaloes, the results available indicate that the genetic variation of these traits can be greater than for dairy cattle (Pander et al. 2002).

Female stayability can be registered for each buffalo as a continuous trait represented by the number of days for which the buffalo stayed in the herd (Martinez et al. 2004) or as a discrete trait, attributing the value 0 to a buffalo that did not stay and a value of 1 for a buffalo that stayed in the herd for a certain time (Silva et al. 2003; Martinez et al. 2005; Queiroz et al. 2007).

In a breeding programme, knowing the genetic and environmental variations of the traits that are used as 
selection criteria is very important. Similarly to reproductive traits, heritability estimates for stayability are low (Hudson \& Van Vleck, 1981; Short \& Lawlor, 1992) irrespective of whether they were registered as continuous variables (with normal distribution) or discrete variables (with binomial distribution) or whether in beef milk cattle or buffalo.

Inclusion of the stayability trait in breeding programmes can permit selection of animals able to have daughters with a higher stayability, so reducting rearing costs and increasing cumulative milk production in the herd.

The aim of this study was to estimate the heritability and evaluate the possibility of using the stayability trait as a selection criterion in buffaloes.

\section{Material and Methods}

The information used in the present study was obtained from female buffaloes born between 1984 and 2001, in nine herds located in the State of São Paulo in Brazil that integrate the Dairy Bubaline Test Program developed by the Animal Science Department of São Paulo State University, Jaboticabal-SP, Brazil. These herds consisted of Murrah breed animals managed on pastures consisting mainly of Brachiaria spp. and Panicum spp.

Dietary supplementation is generally adopted, especially during the dry season (April-September) and consists of chopped sugarcane or grass silage as forage and cotton seed, barley and soy as concentrates. Control of ectoparasites was by pharmaceutical applications, twice a year on average.

Mating was natural or by artificial insemination. Herds were milked twice daily. The milk test was conducted monthly and buffaloes were milked with calves beside them. Calves were weaned when 9 months old.

The data used in the analyses consisted of 1016 Murrah female buffaloes, daughters of 78 sires, extracted from a database with 4219 lactations from 1646 buffaloes. The number of daughters by sire was $12 \cdot 13$, and $33 \%$ of the sires had daughters in more than two herds. To ensure consistency of data, the following were not included in the analyses: animals without age at first calving, animals without milking test data, animals for which the milking test was not started until $60 \mathrm{~d}$ after the first calving and animals for which the first calving registration was outside the age bracket of 740-1260 d.

The stayability (ST) trait was defined as the ability to stay in the herd for one (ST1), two (ST2), three (ST3), four (ST4), five (ST5) or six years (ST6) after the first calving. Those that successfully remained in the herd for the given time were assigned the value 1 whilst the value 0 was assigned to those that had been culled. For each female, the last milking test was considered to be the date on which she was culled. For example in a ST2 analysis, a buffalo that calved for the first time at age $1152 \mathrm{~d}$ $(3 \cdot 15$ years old $)$ and had its last milking test at age $1728 d$
(4.73 years old) was assigned the value 0 (failure) for ST2; i.e. it did not stay in the herd for 2 years after the first calving. It shows that these traits have a binomial response.

The same traits were considered as continuous variables (in days) and denominated the stayability in days (STD) up to one (STD1), two (STD2), three (STD3), four (STD4), five (STD5) or six years (STD6) after the first calving. For the buffaloes that stayed in herd after a specific age $(\mathrm{ST}=1$, indicating success), the STD trait was registered as the values of 365, 730, 1095, 1460, 1825 and $2190 \mathrm{~d}$, respectively, for STD1, STD2, STD3, STD4, STD5 and STD6; when buffaloes were culled $(S T=0)$, the STD trait was registered as the difference in days between the last milking test and the first calving.

The effect of birth season was divided into two seasons owing to few observations in certain months; the season 1 consists of the dry period (April-September) and season 2 the rainy period (October-March). The birth year included the period 1984-2001 for ST1, 1984-2000 for ST2, 1984-1999 for ST3, 1984-1998 for ST4, 1984-1997 for ST5 and 1984-1996 for ST6, considering the opportunity of remaining in the herd after the first calving. Records for buffaloes that had not yet reached the specific ages studied were eliminated. The same was considered for each STD.

For the traits ST1 and STD1, the analysis model considered as the following as fixed effects: breeding herd, birth year and season, and the age at first calving as a (co)variable. Animal and the temporary environment were considered as random effects. For the other traits, the model was the same, excluding age at first calving (AFC) because it was not significant in previous analysis. Analyses using models that included total milk yield during the first lactation, truncated at $270 \mathrm{~d}$, were also realized. The total milk yield during the first lactation effect was considered as two classes: class 1, milk yield up to $1500 \mathrm{~kg}$ and class 2, milk yield $>1500 \mathrm{~kg}$. Any interaction between main effects was not considered in order to avoid classes without variation. The animal model used can be described as:

$\mathrm{Y}=\mathrm{X} \beta+\mathrm{Wa}+\mathrm{e}$

where:

$\mathrm{Y}$ is the observation vector (ST1 up to ST6);

$\beta$ is the fixed effects vector;

$a$ is the random additive genetic effects of the animal;

$\mathrm{e}$ is the residual or temporary environmental random effects;

$\mathrm{X}$ and $\mathrm{W}$ are incidence matrices of the respective effects.

Binomial distribution of the data was assumed for ST at different ages, with the probit link function, in which the ST probability is given by $\mathrm{g}(\mu)=\Phi-1$, in which $\Phi$ is a normal accumulated distribution function and the residual variance was fixed in a unit of the measure $\left(\boldsymbol{\sigma}_{\boldsymbol{e}}^{\mathbf{2}}=\mathbf{1}\right)$. In these analyses, the variance components were estimated by approximate restricted maximum likelihood. For STD at 
Table 1. Number of observations $(N)$, birth year and stayability (ST) success frequency of dairy buffaloes at six specific ages

$\begin{array}{lrll}\text { Traitt } & N & \text { Year } & \begin{array}{l}\text { Success } \\ \text { frequency }\end{array} \\ \text { ST1 } & 1016 & 1984-2001 & 0 \cdot 69 \\ \text { ST2 } & 896 & 1984-2000 & 0 \cdot 63 \\ \text { ST3 } & 742 & 1984-1999 & 0 \cdot 51 \\ \text { ST4 } & 593 & 1984-1998 & 0 \cdot 42 \\ \text { ST5 } & 523 & 1984-1997 & 0 \cdot 36 \\ \text { ST6 } & 415 & 1984-1996 & 0 \cdot 26\end{array}$

${ }^{+}$ST1: Stayability for 1 year after first calving; ST2: Stayability for 2 years after first calving; ST3: Stayability for 3 years after first calving; ST4: Stayability for 4 years after first calving; ST5: Stayability for 5 years after first calving; ST6: Stayability for 6 years after first calving

Table 2. Mean, SD, coefficient of variation (CV), maximum and minimum value for stayability (STD) of dairy buffaloes at six specific ages

\begin{tabular}{lrrlrc} 
Trait & Mean & \multicolumn{1}{l}{ SD } & CV $(\%)$ & Minimum & Maximum \\
STD1† & $325 \cdot 2$ & $73 \cdot 10$ & $22 \cdot 5$ & $73 \cdot 0$ & 365 \\
STD2 & $586 \cdot 9$ & $214 \cdot 10$ & $36 \cdot 5$ & $73 \cdot 0$ & 730 \\
STD3 & $803 \cdot 8$ & $363 \cdot 16$ & $45 \cdot 2$ & $109 \cdot 5$ & 1095 \\
STD4 & $1008 \cdot 0$ & $492 \cdot 60$ & $48 \cdot 9$ & $109 \cdot 5$ & 1460 \\
STD5 & $1172 \cdot 3$ & $630 \cdot 84$ & $53 \cdot 8$ & $109 \cdot 5$ & 1825 \\
STD6 & $1298 \cdot 0$ & $752 \cdot 40$ & $58 \cdot 0$ & $109 \cdot 5$ & 2190
\end{tabular}

${ }^{+}$STD1 were culled 1 year after first calving; STD2 were culled 2 years after first calving; STD3 were culled 3 years after first calving; STD4 were culled 4 years after first calving; STD5 were culled 5 years after first calving; STD6 were culled 6 years after first calving

different ages, normal distribution of the data was assumed, with $\mu=X \beta$ and $\operatorname{Var}=\boldsymbol{\sigma}_{\boldsymbol{e}}^{2}$, and the variance components were estimated by restricted maximum likelihood. All analyses were performed using the ASREML software program (Gilmour et al. 1999), in single-trait analyses, including a parental matrix containing 1694 animals.

ASREML iterates for $n$ iterations unless convergence is achieved first. Convergence is presumed when the REML log-likelihood changes less than $0 \cdot 002 *$ current iteration number and the individual variance parameter estimates change less than $1 \%$. The number of 1000 iterations was used.

\section{Results}

The number of observations, years of birth and ST success frequency (1-6 years after first calving) are shown in Table 1.

For STD, data for each age are shown in Table 2.

Additive genetic variances, heritability coefficients and estimated SE for the traits ST1, ST2, ST3, ST4, ST5 and ST6 are shown in Table 3, and for the traits STD1, STD2, STD3, STD4, STD5 and STD6 they are shown in Table 4.

The two ways of expressing buffalo stayability in the herd, ST and STD, can be considered as the same trait
Table 3. Additive genetic variance $\left(\sigma_{\mathrm{a}}^{2}\right)$, heritability estimates $\left(\mathrm{h}^{2}\right)$ and SE for the traits ST1, ST2, ST3, ST4, ST5 and ST6

$\begin{array}{llll}\text { Trait } & \sigma_{\mathrm{a}}^{2} & \mathrm{~h}^{2} & \mathrm{SE} \\ \text { ST1 } & 0 \cdot 13 & 0 \cdot 11 & 0 \cdot 07 \\ \text { ST2 } & 0 \cdot 20 & 0 \cdot 17 & 0 \cdot 06 \\ \text { ST3 } & 0 \cdot 29 & 0 \cdot 23 & 0 \cdot 06 \\ \text { ST4 } & 0 \cdot 19 & 0 \cdot 16 & 0 \cdot 08 \\ \text { ST5 } & 0 \cdot 15 & 0 \cdot 14 & 0 \cdot 09 \\ \text { ST6 } & 0 \cdot 19 & 0 \cdot 16 & 0 \cdot 10\end{array}$

${ }^{+}$ST1 : Stayability for 1 year after first calving; ST2: Stayability for 2 years after first calving; ST3: Stayability for 3 years after first calving; ST4: Stayability for 4 years after first calving; ST5: Stayability for 5 years after first calving; ST6: Stayability for 6 years after first calving; $\sigma_{a}^{2}=$ additive genetic variance; $\mathrm{h}^{2}=$ heritability; $\mathrm{SE}=\mathrm{SE}$ of the heritability estimate

Table 4. Estimates of additive genetic variance $\left(\sigma_{a}^{2}\right)$, heritability estimates $\left(h^{2}\right)$ and SE for traits STD1, STD2, STD3, STD4, STD5 and STD6

\begin{tabular}{lrll} 
Trait & \multicolumn{1}{c}{$\sigma_{\mathrm{a}}^{2}$} & $\mathrm{~h}^{2}$ & \multicolumn{1}{l}{$\mathrm{SE}$} \\
STD1† & $166 \cdot 65$ & $0 \cdot 05$ & $0 \cdot 06$ \\
STD2 & $6769 \cdot 27$ & $0 \cdot 18$ & $0 \cdot 08$ \\
STD3 & $43469 \cdot 40$ & $0 \cdot 40$ & $0 \cdot 10$ \\
STD4 & $104673 \cdot 00$ & $0 \cdot 49$ & $0 \cdot 11$ \\
STD5 & $134296 \cdot 00$ & $0 \cdot 41$ & $0 \cdot 11$ \\
STD6 & $137899 \cdot 00$ & $0 \cdot 30$ & $0 \cdot 13$
\end{tabular}

${ }^{+}$STD1: were culled 1 year after first calving; STD2: were culled 2 years after first calving; STD3: were culled 3 years after first calving; STD4: were culled 4 years after first calving; STD5: were culled 5 years after first calving; STD6: were culled 6 years after first calving; $\sigma_{\mathrm{a}}^{2}=$ additive genetic variance; $\mathrm{h}^{2}$ heritability; $\mathrm{SE}=\mathrm{SE}$ of the heritability estimate

analysed in different ways. However, the heritability estimates for stayability expressed and analysed in the binary manner (ST) varied from $0 \cdot 11$ to $0 \cdot 23$, while for the same trait analysed continuously (STD) the heritability estimates were higher, varying from $0 \cdot 05$ to $0 \cdot 49$, except for STD1.

\section{Discussion}

In Table 1, as expected, the more advanced the age, the lower the stayability success percentage in the herd. It is also seen that 4 years after the first calving, more than half of the female buffaloes (58\%) were culled. A higher ST mean $(0 \cdot 63 \pm 0 \cdot 45)$ was reported by Short \& Lawlor (1992) in Holstein cows $4-5$ years after the first calving. Peeva \& Ilieva (2007) reported that $25.9 \%$ of buffaloes in a herd in Bulgaria were culled after the first lactation. It is difficult to make comparisons of ST means obtained in this study with others in the literature because of the different definitions of this trait. Moreover, the mean values are strongly dependent on the herd yield, herd region, as well as on management decisions.

Madgwick \& Goddard (1989) reported heritability coefficients of $0.05,0.04,0.01,0.02,0.04,0.02,0.03$, 0.09 and 0.09 , respectively, for stayability up to $1,2,3,4$, 
$5,6,7,8$ and 9 years after first calving for Australian dairy cattle. Short \& Lawlor (1992) analysed stayability in the herd up to 54 and 84 months of age, reporting heritability estimates of 0.06 and 0.05 , respectively. Vanraden \& Klaaskate (1993) analysed the months in milk up to 84 months of age for Holstein cows and reported a heritability estimate of 0.09; the authors also evaluated the cows' stayability in the herd up to $36,42,48,54,60$ and 72 months of age, reporting heritability estimates of 0.03 , $0 \cdot 04,0 \cdot 06,0 \cdot 07,0 \cdot 07$ and 0.08, respectively. In buffaloes, Pander et al. (2002) in a review, reported heritability values of 0.14 for stayability in the herd. In all the studies mentioned above, the heritability estimates for dairy cows' stayability in the herd were lower than the estimates obtained in the present study.

Although STD was analysed assuming it had a error normal distribution, the errors might not be normal and identically distributed. As variance increases very much, stayability time increases. It could explain the higher values for estimated heritabilities and SE for these traits when compared with ST.

In general, the literature shows that for dairy cattle, heritability estimates for ST increase as the cow age increases. However, this was not observed in the present study, in which the highest heritability estimates were observed for ST3 and STD4.

Heritability values similar to the estimates obtained in this present study were reported by Queiroz et al. (2007) and they were $0 \cdot 27,0 \cdot 27$ and $0 \cdot 23$ for ST up to 48,60 and 72 months of age, using the threshold model in Caracu cattle.

Heritability estimates for dairy buffalo stayability in the herd varied from low to medium magnitude, suggesting that sire selection for this trait can lead to a herd genetic improvement. Considering the heritability value estimates and that the expression of this trait occurs later in the female's life, it is better to use in the sire selection the ST3 trait than the ST trait at higher ages. Values of heritability estimates for STD seem to have a lower probability of being true than the estimates for ST, suggesting that stayability could be studied using a binomial response and the threshold model.

Whether to adjust or not adjust stayability in the herd for milk production at first lactation depends on the selection aims. Vollema \& Groen (1996) discussed two ways of considering longevity as a selection aim: uncorrected longevity and functional longevity (corrected for milk production). They also highlighted that the heritability estimates for functional longevity are lower than for uncorrected longevity and the genetic correlation between them is high.

Stayability at age 3 years (ST3) may be suggested to be an adequate trait because: it shows a higher heritability estimate than all other ST; it contains a larger number of observations in the records, which permits better accuracy in the prediction of breeding value; owing to the serial nature of STAY to a specific age, selection for ST3 should have a favourable influence on ST to later ages (Snelling et al. 1995); and it is obtained earlier during the reproductive life of the animals, reducing the generation interval. However, further studies are needed to determine genetic and phenotypic correlations among studied traits.

Recently, traits related to longevity have been included in dairy cattle breeding programmes in order to promote the sustainability of the production system, reducing costs. However, care is required in recommending selection based on traits that can only be determined later in the female's life. It may prolong the generation intervals and reduces the annual genetic progress. However, a fact that happens in the herds is that stayability is only measured after the first lactation, at a minimum of 36 months of age. So an alternative could be the use of traits correlated with longevity and measured earlier in the female's life, such as milk production at the first lactation and conformation traits. Because of this, further studies of genetic variability in longevity traits are required in dairy buffaloes.

\section{Conclusions}

Heritability estimates for stayability obtained in the present study suggest that the trait shows genetic variation in the considered population. However, further studies are necessary to determine genetic and phenotypic correlations among stayability at different ages.

The authors thank the buffalo breeders of the milk test programme who provided the data for the study and also to the Conselho Nacional de Desenvolvimento Científico e Tecnológico $(\mathrm{CNPq})$ and to the Fundação de Apoio à Pesquisa do Estado de São Paulo (FAPESP) for financial support.

\section{References}

Gilmour AR, Cullis BR, Welham SJ \& Thompson R 1999 ASREML Reference Manual NSW Agriculture Biometric Bulletin 3 Orange, NSW Australia: NSW Agriculture

Hudson GFS \& Van Vleck LD 1981 Relations between production and stayability in Holstein cattle. Journal of Dairy Science 64 2246-2250

Madgwick PA \& Goddard ME 1989 Genetic and phenotypic parameters of longevity in Australian dairy cattle. Journal of Dairy Science $\mathbf{7 2}$ 2624-2632

Martinez GE, Koch RM, Cundiff LV, Gregory KE \& Van Vleck LD 2004 Genetic parameters for six measures of length of productive life and three measures of lifetime production by 6 years after first calving for Hereford cows. Journal of Animal Science 82 1912-1918

Martinez GE, Koch RM, Cundiff LV, Gregory KE \& Van Vleck LD 2005 Genetic parameters for stayability, stayability at calving, and stayability at weaning to specified ages for Hereford cows. Journal of Animal Science 83 2033-2042

Pander BL, Dhaka SS \& Singh S 2002 Genetic Improvement of lifetime performance and longevity of Indian Buffaloes. In: World Congress on Genetics Applied to Livestock Production 7 Montpellier CD-ROM

Peeva T \& Ilieva Y 2007 Longevity of buffalo cows and reasons for their culling. Italian Journal of Animal Science 6 378-380

Queiroz SA, Figueiredo G, Silva JAIIV, Espasandin AC, Meirelles SL \& Oliveira JA 2007 [Estimates of genetic parameters of stayability to ages 48, 60 and 72 months in Caracu cows]. Revista Brasileira de Zootecnia 36 1316-1323 
Silva JAIIV, Eler JP, Ferraz JBS \& Oliveira HN 2003 [Genetic analysis of stayability Nelore cows]. Revista Brasileira de Zootecnia 32 598-604

Short TH \& Lawlor TJ 1992 Genetic parameters of conformation traits, milk yield, and herd life in Holsteins. Journal of Dairy Science $\mathbf{7 5}$ 1987-1998

Snelling WM, Golden BL \& Bourdon RM 1995 Within herd genetic analyses of stayability of beef females. Journal of Animal Science $\mathbf{7 3}$ 993-1001

Tonhati H, Ceron Muñoz MF, Oliveira JA, Lima ALF, Albuquerque LG \& Faro L 2008 Test-day milk yield as a selection criterion for dairy buffaloes (Bubalus bubalis Artiodactyla, Bovidae). Genetics and Molecular Biology 31 674-679

Vanraden PM \& Klaaskate EJH 1993 Genetic evaluation of length of productive life including predicted longevity of live cows. Journal of Dairy Science 76 2758-2764

Vollema AR \& Groen, AF 1996 Genetic parameters of longevity traits of an upgrading population of dairy cattle. Journal of Dairy Science $\mathbf{7 9}$ 2261-2267

Vukasinovic N, Moll J \& Kunzi N 1997 Analysis of production life in Swiss Brown cattle. Journal of Dairy Science 80 2372-2579 